\title{
Evaluating Net-Zero Energy Houses from the U.S. Department of Energy Solar Decathlon 2011
}

\author{
Jordan WALLPE ${ }^{1}$, William HUTZEL ${ }^{2}$, Gregory LASKER ${ }^{3}$, and Clark CORY ${ }^{4}$ \\ ${ }^{1}$ Department of Mechanical Engineering Technology, Purdue University, Knoy Hall, \\ West Lafayette, IN 47906; email: jwallpe@purdue.edu \\ ${ }^{2}$ Department of Mechanical Engineering Technology, Purdue University, Knoy Hall, \\ West Lafayette, IN 47906; email: hutzelw@purdue.edu \\ ${ }^{3}$ Department of Building Construction Management, Purdue University, Knoy Hall, \\ West Lafayette, IN 47906; email: glasker@purdue.edu \\ ${ }^{4}$ Department of Computer Graphics Technology, Purdue University, Knoy Hall, \\ West Lafayette, IN 47906; email: ccory@purdue.edu
}

\begin{abstract}
The Solar Decathlon is a two year, international project where university students compete to design, build, and test energy-efficient, net-zero homes. By definition, net-zero energy houses annually produce as much electricity as they consume. The 2011 Solar Decathlon, held in Washington D.C., had 19 university teams from around the world.

Unfortunately, many past Solar Decathlon houses have traditionally been very costly. However, the 2011 Solar Decathlon was the first competition to have an affordability contest. The affordability contest required each home to be valued under an estimated builder's cost of $\$ 250,000$, forcing the teams to select economically feasible solutions for creating net zero energy houses. Finding super-efficient, solarpowered, and affordable houses can be done by evaluating the contests associated with the Solar Decathlon 2011.

The main cost-effective and energy saving components were discovered by researching final competition scoring of each specific contest. Heat pump water heaters, properly sized photovoltaic arrays, and HVAC systems with proper dehumidification were the main findings of this research. Fortunately, all of these findings can immediately be implemented into the design of net-zero energy housing with off-the-shelf products.
\end{abstract}

\section{INTRODUCTION}

The Solar Decathlon is a two year, international project where university students compete to design, build, and test energy-efficient, net-zero homes. By definition, net-zero energy houses annually produce as much electricity as they consume. The 2011 Solar Decathlon, held in Washington D.C., had 19 university teams from around the world. The competition was held on the West Potomac Park National Mall and attracted a remarkable 357,000 hours visits (U.S. D.O.E., 2011).

As the name implies, the Solar Decathlon 2011 had 10 equally-weighted contests worth 100 points each in which each house competed in. Both quantitative and qualitative contests took place. The quantitative contests were Comfort Zone, Hot Water, Appliances, Home Entertainment, and Energy Balance. On the other hand, the subjective (qualitative) contests were Architecture, Market Appeal, Engineering, 
Communications, and Affordability. All subjective contests were scored by a jury of industry professionals.

The houses competed for a total of nine days filled with cloudy and humid weather. Surprisingly, several teams demonstrated their solar houses could still reach net-zero during this week. The competition was a great platform to find proven examples of affordable, energy saving systems. Several systems that should be considered when designing a net-zero energy house were realized by analyzing contests and the houses that competed in the competition.

\section{Purpose}

The residential sector in the United States consumed 21.21 quadrillion Btu's, or $22.4 \%$ of all energy consumed in the United States in 2005 (U.S. Energy Information Administration, 2009). Of those 21.21 quadrillion Btu's, 39.6\% or 124.74 billion dollars was spent on electricity (U.S. EIA, 2009). To put this in perspective, if all electricity consumed by the housing sector came from coal, the coal pile would fill an entire NFL football field several hundred feet tall. Furthermore, most of the energy consumed in the residential sector comes from coal, as our country receives $48 \%$ of all electricity from coal (U.S. EIA, 2010).

Depending on location, net-zero energy homes have traditionally been difficult to implement because of high cost. The United States Department of Energy Solar Decathlon has been a biannual competition since 2002, aiming to lower the cost of solar living and reduce unnecessary energy consumption in the residential sector.

The past four competitions had no limit on the value of each home as several houses reached the million dollar mark, a price tag the average American cannot afford. Consequently, the 2011 Solar Decathlon was the first competition to have an affordability contest. The affordability contest required each home to be valued under an estimated builder's cost of $\$ 250,000$, forcing the teams to select economically feasible solutions for creating net zero energy houses.

This research paper demonstrates super-efficient, solar-powered and affordable houses by evaluating the Solar Decathlon 2011. The results of analyzing the houses in the competition contain affordable, energy conserving characteristics that, if implemented, will reduce energy consumption in the residential sector. This research answers this most important question of, "What affordable engineering systems provided significant energy savings in the Solar Decathlon 2011?"

\section{Assumptions}

It was assumed that competition data was unaltered during the collection as the event organizers did a great job of recording each house identically. This data is assumed to represent net-zero energy homes as well. The Affordability results included all labor and a $20 \%$ contingency within each specification division.

Data collection for this research was limited to the houses that competed in the Solar Decathlon 2011. The cost-effectiveness or affordability of each house was limited by the official competition scoring estimate spreadsheet. Lastly, no other energy sources were considered except for solar photovoltaic, solar thermal, and electricity delivered from the utility grid. 


\section{Methodology}

First off, the Solar Decathlon 2011 provided an excellent framework to gather valuable information over current net-zero energy housing. Mainly because 19 potentially net-zero energy houses were identically measured and reviewed without bias, providing a very good research platform. The competition officials released all scoring documentation for each house at the conclusion of the Solar Decathlon 2011. Both quantitative and qualitative contest results were made publicly available through the DOE's Solar Decathlon website.

This paper focuses on realizing engineering systems in affordable, net-zero energy houses. Several quantitative contests had a great effect on the outcome of the engineering performance of the house. The Hot Water, Comfort Zone, Energy Balance, and Affordability contests were used to measure and compare each house.

\section{RESULTS}

Upon completing a review of all the homes and their performance, a list of affordable, energy saving systems was identified. During the Solar Decathlon 2011, the type of water heating and heating, ventilation, and air conditioning system used in each home played a significant role.

The most dominant independent variable that every house had to deal with was the weather during the competition. Overall, the competition week was extremely humid and particularly warm. Figure 1 showcases the uncomfortable outdoor conditions. Furthermore, this weather diminishes the possibility of having an abundance of sunshine. Figure 2 illustrates the global horizontal solar radiation that was available during the contests as well. Unfortunately, only four days ever reached over $500 \mathrm{~W} / \mathrm{m}^{2}$. In contrast, standard testing conditions for rating photovoltaic modules is set at $1000 \mathrm{~W} / \mathrm{m}^{2}$. Many teams had a hard time competing with poor weather and less-than-friendly amounts of sunshine.

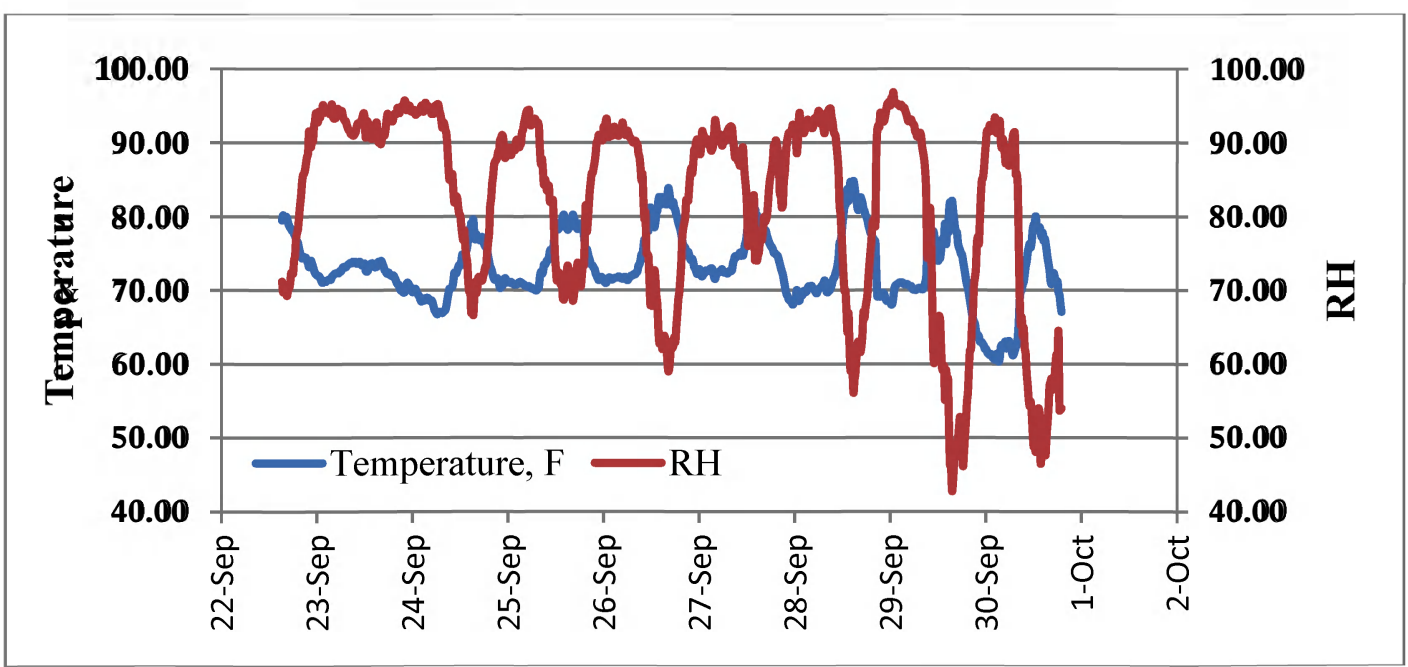

Figure 1. Outdoor temperature and relative humidity. Solar Decathlon 2011. 


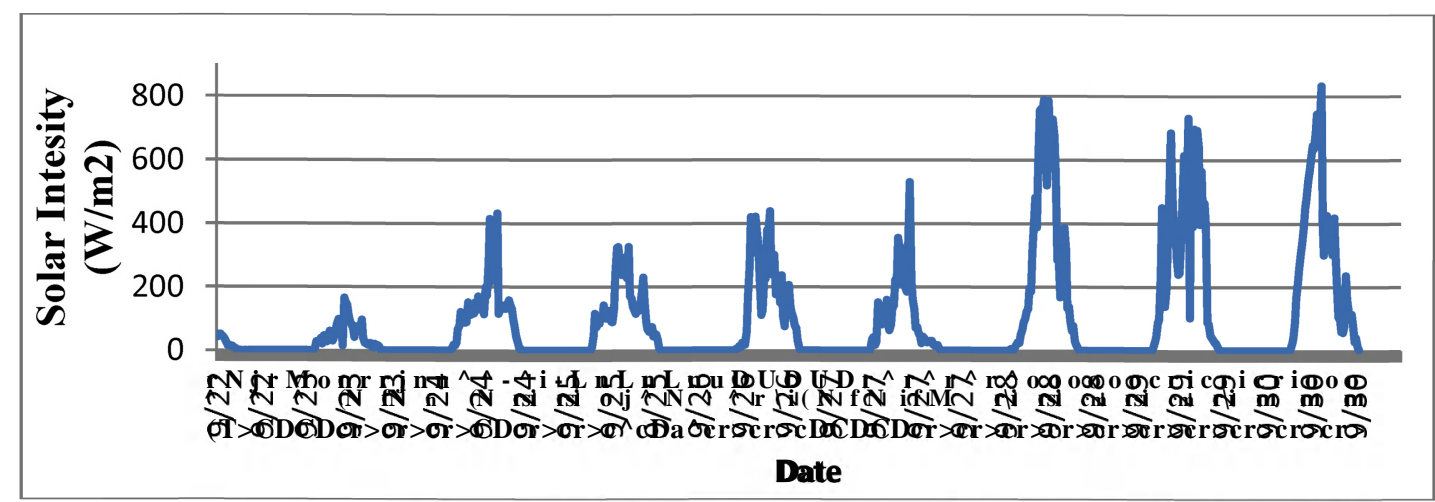

Figure 3. Solar power available during the competition week. Retrieved from U.S. DOE. SD2011_Scores_Final Spreadsheet

\section{Water Heating}

One of the ten contests during the competition, worth 100 points, required each house to draw hot water from the shower 16 times. Each draw had to have at least 15 gallons of water at $110^{\circ} \mathrm{F}$, all within ten minutes. Most competition days had two or three draws, testing the hot water systems in all houses to mimic showering in a typical house.

Out of the seven teams that reached net-zero, five houses had heat pump water heaters. The remaining 12 homes used solar thermal systems to generate hot water. As stated earlier, the competition week was fairly cloudy, with only four days reaching over $500 \mathrm{~W} / \mathrm{m} 2 \mathrm{z}$ of global horizontal solar radiation as seen in Figure 3.

The lack of sunshine during the competition proved difficult for the teams without heat pump water heaters to reach net-zero. Many homes had to use back up resistant electric water heaters to earn hot water points. On the other hand, teams with a heat pump water heater used on average a little more than $2 \mathrm{kWh}$ of electricity a day. The 5 teams that utilized a heat pump water heater finished in the top three positions in the Hot Water contest. Furthermore, four of seven teams that tied for first place had a heat pump water heater.

Depending on the end-user's hot water demand solar thermal systems may be the best option. However, in the confines of the Solar Decathlon competition, adequate solar power was not available. Furthermore, the average solar thermal system in the Solar Decathlon was $\$ 7100$, compared to the average $\$ 1500$ of heat pump water heaters. Note that the solar thermal systems associated with New Zealand, Maryland, Canada, China, and New York were not included in this average because their hot water was used for HVAC systems as well. It was very visible that heat pump water heaters were the most affordable solution to generating hot water.

\section{Comfort Zone}

The Comfort Zone contest required each house to be within very specific temperature and relative humidity set points. During specified hours, mostly from 3PM through 9AM the next morning, the houses had to be between $71-76^{\circ} \mathrm{F}$ and under $60 \%$ relative humidity.

Many houses had difficulty earning points in the comfort zone contest. Of the 19 homes, 13 had some sort of ductless mini-split HVAC system. These are described 
as having a condensing unit outdoor that is connected to one or two indoor evaporator units. These are either in open space, usually mounted on a wall up high to give a great temperature control for a specific zone. Otherwise, the indoor evaporator units were tied into a ducted distribution system.

Ductless mini split systems are very good at keeping the desired zone within temperature set points. However, the weather during the competition largely affected dehumidification efforts of each house. Relative humidity levels, as seen in Figure 1, were very high at night, over $90 \%$. Dehumidification efforts made by several teams were unsuccessful. Therefore, many teams tried to stay within the temperature limits as temperature was worth $75 / 100$ of the Comfort Zone points. At the same time, many teams neglected earning the additional 25 points for proper indoor humidity. Unfortunately, many teams with ductless mini-splits could not bring the relative humidity less than $60 \%$ and simultaneously be within the temperature limits.

Figure 3 illustrates the performance of several teams' HVAC systems. It should be noted that a few HVAC systems were not included in this research because they were unique and difficult to prove reliable and/or affordable from competition results. New York had an absorption cooling system which pushed the envelope for residential buildings. Team Illinois had a CERV unit, which combined an air conditioning cycle into an energy recovery ventilator. Lastly, Team China and Team New Jersey both utilized radiant heating and cooling technology.

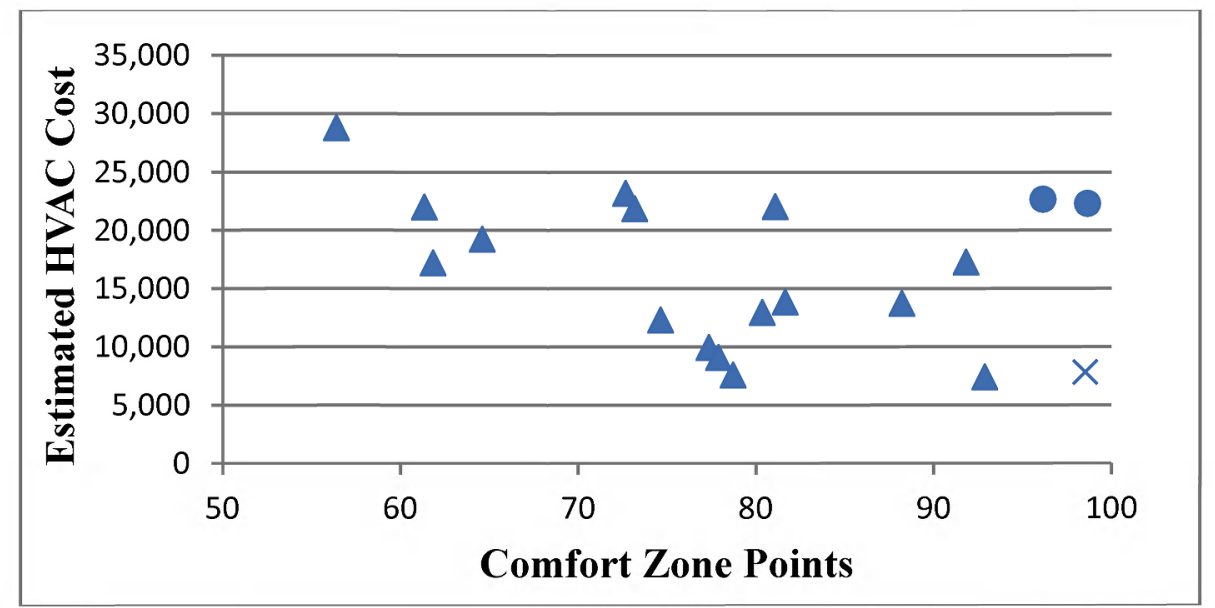

Figure 3. Comfort Zone scoring and affordability results. Solar Decathlon 2011.

From Figure 3, the top two scoring ductless mini splits (shown as dots) are shown to be a bit more costly. This is because a separate dehumidification system was used. Both teams did an exceptional job of removing moisture from the indoor air, while at the same time keeping within the temperature set points. However, each system was valued over $\$ 20,000$.

There was only one traditional forced air HVAC system installed (shown as $\mathrm{X})$. The system was used in the Purdue INhome. In detail, the HVAC system was a two compressor heat pump unit with a SEER rating of 19. It was paired with an air handling unit that had a variable speed drive fan. This system did a great job of removing moisture while keeping within the temperature set points. Furthermore, the INhome had an indoor plant wall with about $12 \mathrm{~S}$.F. of living plants acting as a return 
grille to the HVAC system. This was an additional latent load that the system handled exceptionally well. Unlike other houses, an additional dehumidification system was not needed, which kept costs down.

By looking at Figure 4, it is easy to see the best performing and most affordable system is the forced air unit. Unfortunately, it is not accurate to say that a forced air system is the best way to keep within comfort zone when only one team had a traditional forced air system. However, it can be said that, in a very humid climate, many ductless mini splits would not perform ideally without separate dehumidification systems. What should be noted is that ultra-efficient and energy saving forced air systems are available and affordable today.

\section{Energy Balance}

The Energy Balance contest quantitatively determined whether or not a house was net-zero during the week long competition. The amount of electricity both generated and consumed by the house was recorded the same way for each house. The size of the photovoltaic array, electricity consumption of the house, and cost of the photovoltaic array were also considered to determine which system affordably reached net-zero energy status.

Figure 4 showcases which houses were able to reach net zero. Only $7 / 19$ teams were able to overcome the cloudy week. The seven teams that reached net zero were sized appropriately. Of the seven teams that reached net zero, the average array size was $8.4 \mathrm{~kW}$ and cost was $\$ 48,700$ ( $\$ 5.8 /$ Watt). The other 12 teams had an average array size of $6.9 \mathrm{~kW}$ and cost of $\$ 31,250$ ( $\$ 4.5 /$ Watt). Some houses did not have an adequately sized array to reach net-zero. Tidewater Virginia and Parsons New Stevens had $4.0 \mathrm{~kW}$ and $4.2 \mathrm{~kW}$ arrays respectively. Granted, the overall photovoltaic cost was lower than those who reached net-zero; perhaps these teams wanted to partially off-set electric consumption.

There are a lot of factors that determine if a home becomes net zero or not. Of course, a majority of the factors deal with electrical demand, but a few such as tilt angle and actual size of the array are critical. For example, Appalachian State used one of the top performing solar photovoltaic modules available. The team used Sanyo HIP 195 bi-facial modules, for a total size of $10.5 \mathrm{~kW}$. Unfortunately, these modules were mounted horizontally at 0 degrees and the total energy produced was reduced because of this (competition rules limited the height of each house to be 18 feet offgrade). The rule of thumb for a fixed mount array is to have the tilt angle matching the latitude. This normally optimizes annual energy output (NREL, 2011). 


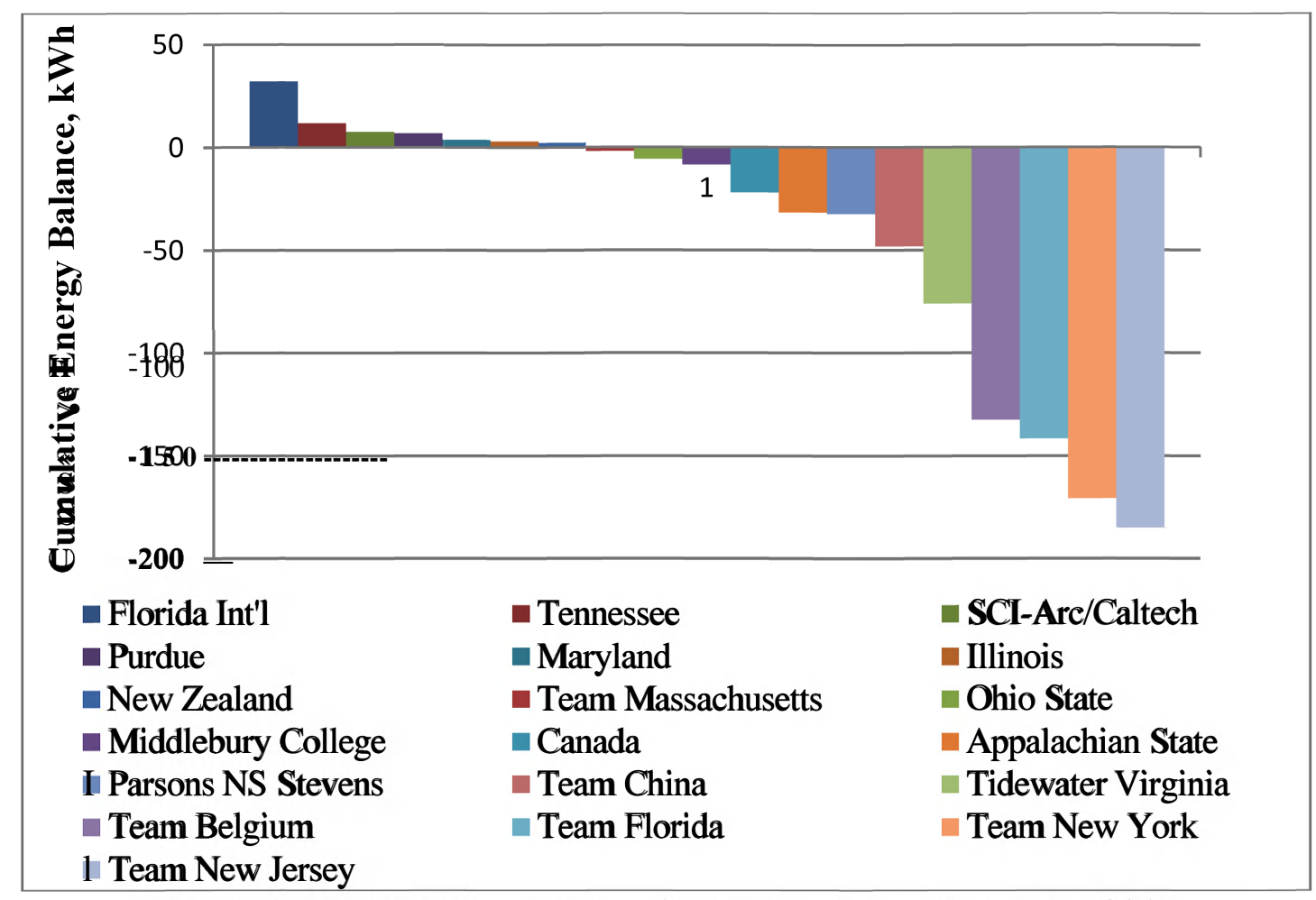

Figure 4. Final Energy Balance Standings. Solar Decathlon 2011.

From looking at the competition data it is easy to see that overall Energy Balance performance is partially based on array size and tilt angle as stated above. However, all electric loads of the houses would have to be taken into consideration to pin point where a majority of the electricity for each house was consumed. Nonetheless, no two houses were identical and the unique features of each home are what gave that specific home its value to the homeowners. All of the teams that reached net-zero did a very good job of estimating competition electric loads of their individual houses. This is a critical step in sizing a photovoltaic array.

\section{CONCLUSION}

Sincerely cost-effective and energy saving components were discovered by researching final scoring, as this competition clearly encouraged teams to build lowcost energy efficient homes. Heat pump water heaters, properly sized photovoltaic arrays, and HVAC systems with proper dehumidification were the main findings of this research. By mitigating unnecessary costs associated with traditional solar powered homes, such as an oversized or undersized photovoltaic array, low-cost efficient housing is becoming more practical and mainstream.

It should be noted that many of these system were not unusual, but mostly offthe-shelf products placed in very efficient buildings. A competition rule mandated that all products placed in the house be commercially available to the general public. Technically, teams could buy a thousand parts and assemble them together piece by piece. However, that proved expensive and unreliable as seen in the Hot Water contest results. Heat pump water heaters are easy to install, superbly energy efficient, 
and most of all affordable. HVAC systems must be high-performing, energy efficient, and affordable, which can be done with traditional forced air systems on the market today. Lastly, a house can become net-zero when the photovoltaic array is properly sized to match building loads and then properly installed. A net zero house is feasible today by utilizing these proven examples of affordable and energy saving systems.

All houses from the Solar Decathlon 2011 and previous competitions can be found on www.solardecathlon.gov. The next Solar Decathlon competition will be held in 2013 in Irvine, California. The second Solar Decathlon Europe will be held in Madrid, Spain in 2012. Lastly, China is hosting the Solar Decathlon China in 2013.

\section{REFERENCES}

Brearley, D. (2010, February \& March). Winning Ways: 2009 Solar Decathlon. Home Power, 14(1), 88-95.

Department of Energy. (2010). About DOE. Retrieved from http://www.energy.gov/about/index.htm

National Renewable Energy Laboratory. (2011). PVWatts. Retrieved from http://www.nrel.gov/rredc/pvwatts/changing_parameters.html\#tilt_angle

U.S. Department of Energy. (2009). Scoring Backup. Retrieved from http:// www.solardecathlon.gov/past/2009/final_results.html

U.S. Department of Energy. (2010). Solar Decathlon. Retrieved from http://www.solardecathlon.gov/contest_affordability.html

U.S. Department of Energy Solar Decathlon 2011. (2011). Exhibit House Visits.

U.S. Energy Information Administration. (2009). Annual Energy Outlook 2009, p.58. Retrieved from http://www.eia.gov/oiaf/aeo/pdf/0383\%282009\%29.pdf

U.S. Energy Information Administration. (2010). Annual Energy Outlook 2010, p.58. Retrieved from www.eia.doe.gov/oiaf/aeo/ 